\title{
Post-production Losses in lodine Concentration of Salt Hamper the Control of lodine Deficiency Disorders: A Case Study in Northern Ethiopia
}

\author{
Dawit Shawel ${ }^{1,2}$, Seifu Hagos ${ }^{1,2}$, Carl K. Lachat ${ }^{2,3}$, Martin E. Kimanya ${ }^{4}$, and Patrick Kolsteren ${ }^{2,3}$ \\ 'Department of Public Health, Mekelle University, Mekelle, Ethiopia, ${ }^{2}$ Department of Food Safety and Food Quality, Faculty of Bioscience \\ Engineering, Ghent University, Belgium, ${ }^{3}$ Nutrition and Child Health Unit, Department of Public Health, Prince Leopold Institute of \\ Tropical Medicine, Antwerp, Belgium, and ${ }^{4}$ Directorate of Food Safety, Tanzania Food and Drugs Authority, Dar es Salaam, Tanzania
}

\begin{abstract}
Iodine is essential for good function of the thyroid, and its deficiency is of public-health importance in Ethiopia. Iodization of salt is an effective and sustainable strategy to prevent and control iodine deficiency in large populations. The effectiveness of salt-iodization programmes depends on the conservation of iodine concentration in salt at various stages of the supply-chain. The overall objective of the study was to assess the loss of iodine in salt from production to consumption and to estimate the proportion of adults, especially pregnant women, at risk of dietary iodine insufficiency. A cross-sectional study was conducted during February-April 2007 in northern Ethiopia. Iodine concentrations of salt samples from producers $(n=41)$, retailers $(n=7)$, and consumers $(n=32)$ were determined using iodiometric titration. A risk assessment was conducted for dietary iodine insufficiency among adults, including pregnant women, using a semi-probabilistic approach. The concentration of iodine in the sampled salts decreased by $57 \%$ from the production site to the consumers. The assessment of exposure showed that adults in $63 \%(\mathrm{n}=20)$ of the households, including $90 \%(\mathrm{n}=29)$ with pregnant women, were at risk of insufficient iodine intake. A monitoring and evaluation system needs to be established to ensure adequate supply of iodine along the distribution chain. Special attention is needed for the retailers and consumers. At these levels, dissemination of information regarding proper storage and handling of iodized salt is necessary to address the reported loss of iodine from salt.
\end{abstract}

Key words: Cross-sectional studies; Iodine; Iodine deficiency; Salt; Ethiopia

\section{INTRODUCTION}

Iodine is an essential trace element for good function of the thyroid, which, in turn, is indispensable for optimal health. Deficiency in iodine is the single most common cause of preventable mental retardation and brain damage in the world. Iodine deficiency disorders manifest in decreased childsurvival rates, goitre, and overall impaired growth and development (1-3).

The global database of the World Health Organization (WHO) shows that, during 1993-2003, iodine

Correspondence and reprint requests should be addressed to:

Dr. Patrick Kolsteren

Nutrition and Child Health Unit

Prince Leopold Institute of Tropical Medicine

Nationalestraat 155 B-2000, Antwerp

Belgium

Email: pkolsteren@itg.be

Fax: 003232476543 deficiency was still a public-health problem in 54 countries, and an estimated two billion individuals had an insufficient dietary iodine intake (4). In Ethiopia, around 28 million people suffer from goitre, and more than 35 million people are at risk of iodine deficiency. More importantly, 50,000 perinatal deaths are related to iodine deficiency each year in Ethiopia. The education potential of the nation is unattained as iodine deficiency may cause an intelligence quotient reduction of 13.5 points (5). The problem is both a threat to the productivity of the workforce and a cause of cretinism and mental retardation. These factors are estimated to lead to an enormous loss of gross domestic product. In Ethiopia, this has been estimated at nearly US\$ 1 billion over the 2000-2005 period (6).

Iodization of salt is an effective and sustainable public-health strategy to prevent and control iodine deficiency and has been ongoing in several countries for over 60 years. Iodization of salt is cur- 
rently undertaken following the universal salt-iodization initiative (7-9). Iodine is added to salt in the form of potassium iodide or iodate. At the point of production, it is recommended that the salt contains 20-40 mg of iodine per $\mathrm{kg}$ (10).

The actual availability of iodine from iodized salt at the consumer level can vary widely due to a number of factors: variability in the amount of iodine added during iodization, poor mixing resulting in uneven distribution within the batches or bags produced and instability of iodine in the salt. These factors affect how much iodine is finally available for consumption. Various factors, such as moisture content of salt, ambient humidity, light, heat, impurities in salt, alkalinity or acidity, and the form (potassium iodide or iodate) in which the iodine is present, affect iodine stability in salt (11). Hence, the effectiveness of salt-iodization programmes to deliver adequate amounts of iodine at the consumer level largely depends on the stability of iodine $(10,12-24)$.

According to the Ethiopia Demography and Health Survey 2005 , only around $4.2 \%$ of the Ethiopian population uses iodized salt (25). Recently, a national iodization strategy was developed, and a 3-5-year supply of potassium iodate has been distributed to salt suppliers. To warrant adequate supplementation of iodine at the consumer level, monitoring and evaluating the concentration of iodine in salt (in particular by measuring iodine concentrations and documentation of losses) is an essential element of a programme to eliminate iodine deficiencies. Additionally, it is important to monitor what percentage of the population remains at risk of insufficient intake of iodine. Therefore, this study estimated the loss of iodine from production (iodization) to the consumption at the household level and performed an assessment of exposure to estimate the adequate coverage of iodine intake by adults and pregnant women in Tigray region northern Ethiopia.

\section{MATERIALS AND METHODS}

\section{Study region}

A cross-sectional study was conducted in Tigray region in northern Ethiopia from February to April 2007. The region is mountainous, with an average elevation of 1,972 metre above the sea-level. According to the Central Statistical Agency of Ethiopia, the region had a predominantly rural population of approximately 4,334,996 in 2005. The total goitre rate in the region was estimated to be $35.6 \%$, and approximately $9.3 \%$ of the population reportedly knows the importance of iodized salt (26).

\section{Sampling of salt}

The region is mainly served by one small-scale regional producer of iodized salt in Mekelle, the capital city of the region. Potassium iodate is used for iodization of salt. The iodized salt is packed by the producer in a $1-\mathrm{kg}$ or a $50-\mathrm{kg}$ polyethylene bag. According to the needs of consumers, this can be repacked in smaller plastic bags or paper packets. The iodization is performed on a weekly basis for about 4-5 hours a day. Four production days were randomly identified for sample collection at the production site. In total, 41 samples were collected at 30-minute intervals during the process of iodization over four days. The samples were taken immediately after salt had been iodized. Approximately $100 \mathrm{~g}$ of iodized salt was taken for each analysis. Samples were transferred to an airtight plastic cup and subsequently labelled and coded.

\section{Sampling from retailers and consumers}

To determine the concentration of iodine in the iodized salt at the retailer and consumer levels, we followed the distribution of the iodized salt from the production site to the households. A town named Wukro, $50 \mathrm{~km}$ away from the production site in Mekelle city, was selected for the sampling. Wukro is the study site for the community health internship programme of the College of Health Science of the Mekelle University. A team of 15 undergraduate public-health students was trained as data collectors for the study. The producer sold salt to seven retailers in the study area. All retailers were included in the study. In total, seven samples were obtained from the retailers.

After obtaining informed consent from the retailers, a list of customers who were supplied with iodized salt for the past two months by the retailer was compiled. In total, 32 salt samples were collected from all the households based on this list. All the consumers on the list were traced, and salt samples were collected from their households.

A sample of approximately $100 \mathrm{~g}$ of iodized salt was taken from the retailers and consumers. The samples were transferred to an airtight plastic cup and subsequently labelled and coded. All the salt samples were transported to the Laboratory of Analytical Chemistry, Mekelle University, and were analyzed immediately after arrival. It took about two hours to transport the samples to the laboratory.

\section{Analysis of samples}

To determine the concentration of iodine in the salt, trained laboratory technicians analyzed all the samples using iodiometric titration method ap- 
proved by the World Health Organization/United Nations Children's Fund/International Council for the Control of Iodine Deficiency Disorders (WHO/ UNICEF/ICCIDD) (10). Each sample was analyzed in triplicate. The average of these was taken as iodine concentration of the sample. The conversion of the titration results to iodine concentrations was done using a standardized table as per recommendations of the ICCIDD/MI/UNICEF/WHO (27).

\section{Exposure assessment}

We carried out an assessment of exposure for adults and pregnant women who might consume iodized salt with the iodine concentrations at the production, retailer and household levels. We carried out the assessment of exposure for salt at the production level because the producer sells salt directly to consumers in a small shop located nearby the production site. The exposure assessment was conducted for the daily intake of iodine using a semiprobabilistic approach and by combining the average reported salt intake of $4.6 \pm 3.5 \mathrm{~g}$ per person per day reported by Abuye et al. for adults in Ethiopia with the intake of iodine ( $\mu \mathrm{g} / \mathrm{day})$ from the different samples (28).

The WHO, UNICEF, and ICCIDD recommend that the daily intake of iodine should be $150 \mu \mathrm{g}$ for adults aged over 12 years and $250 \mu \mathrm{g}$ for pregnant and lactating women (10). The currently-used tolerable upper intake level for adults and pregnant women is $600 \mu \mathrm{g}$ per day according to the European Commission's Scientific Committee for Food (EC/SCF) and 1,000 $\mu \mathrm{g}$ per day according to the Institute of Medicine (29).

As Thomson et al. did, we used a semi-probabilistic approach for the assessment of exposure with a fixed value for salt intake (30). This approach is appropriate when little variation in salt intake is expected. The diet of the households in the study area is monotonous, and as most households are poor and have a similar socioeconomic status, food intake consequently is expected not to vary much among different households. Hence, little variation in salt intake is anticipated.

We first performed the assessment of exposure using iodine concentrations from our samples. To evaluate the actual concentration of iodine in the diet consumed, we subsequently repeated this assessment taking into account an additional loss of $20 \%$ of iodine concentrations during the cooking process as estimated by the WHO (10).

\section{Analysis of data}

Data were entered into MS Excel and were analyzed using the Stata software (Intercooled Stata version
10) (Statacorp, College Station, Texas, USA). In the case of severe departure from normality, data were transformed logarithmically until a normal distribution was obtained. All analyses were carried out with a significance level of 5\%, and all tests were two-sided. Analysis of variance (ANOVA) test was used for exploring the differences of iodine concentrations in the salt between sampling levels and days of sampling.

\section{Ethical clearance}

The Ethical Committee in the Mekelle University approved the study. Informed consent was obtained from the subjects involved in the study. The study subjects were informed about the objective of the study. The participants were allowed to consider their participation and given the opportunity to withdraw from the study at any point in the course of the study if they wished to do so.

\section{RESULTS}

\section{Concentration of iodine in salt at production site}

In total, 41 salt samples from the production site were analyzed. The concentration of iodine in salt found at the production site was $57.9 \pm 15.31 \mathrm{mg} /$ $\mathrm{kg}$. The mean iodine concentration was not different between the days of sampling $(p=0.14)$. None of the samples had an iodine concentration below the minimum recommended iodine concentration of $20 \mathrm{mg} / \mathrm{kg}$, and the maximum concentration found was $98.4 \mathrm{mg} / \mathrm{kg}$.

\section{lodine concentration in salt at retailers}

The concentration of iodine in salt found at the retailers was $41.3 \pm 14.3 \mathrm{mg} / \mathrm{kg}$. None of the samples had an iodine concentration of below $20 \mathrm{mg} / \mathrm{kg}$. There was no difference in the mean concentration of iodine in salt from different retailers $(\mathrm{p}=0.45)$.

lodine concentration in salt at consumer level

The mean concentration of iodine in salt sampled from the study households was $25.1 \pm 22.5 \mathrm{mg} / \mathrm{kg}$. The iodine concentration ranged from $1.1 \mathrm{mg} / \mathrm{kg}$ to $69.8 \mathrm{mg} / \mathrm{kg}$ in the samples.

The average decrease in iodine concentration of salt samples from the production to the retailer level was $29 \%$ and 50\% from the retailer to the consumer level. On average, the iodine concentration was reduced by $57 \%$ from the production to the consumer level (Fig.).

\section{Assessment of exposure}

Using the iodine concentrations as determined at the production, retailer and consumer levels, the 
Fig. Iodine concentration $(\mathrm{mg} / \mathrm{kg}$ ) of iodized salt at production, retailer and consumer levels (mean and 95\% confidence interval)

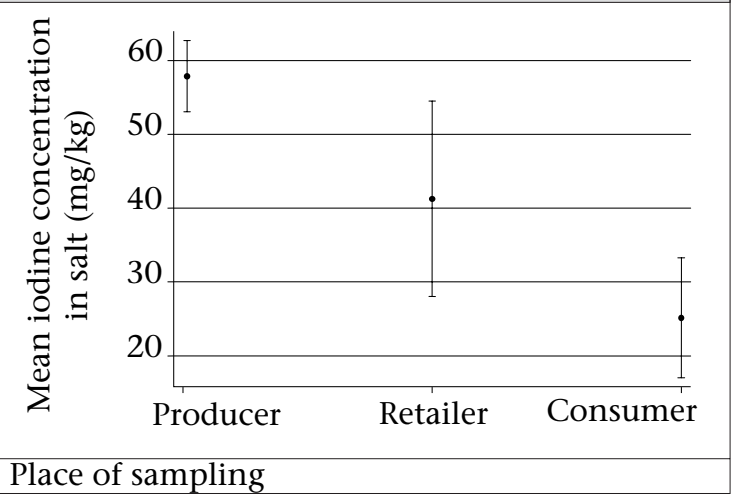

daily intake of iodine was estimated to be $266 \mu \mathrm{g}$ per person per day, $238 \mu \mathrm{g}$ per person per day, and $119 \mu \mathrm{g}$ per person per day respectively.

The table shows that $27 \%$ and $63 \%$ of the adults were exposed to the insufficient intake of iodine when consuming salt with iodine concentrations as observed at the retailer and household levels. Most (90\%) pregnant women consuming salt with an iodine concentration observed at the household level were exposed to the insufficient intake of iodine. The tolerable upper intake levels of iodine did not exceed when consuming salt from the different sources. Taking into account an additional loss due to cooking, only a minority of the pregnant women was expected to have sufficient intakes of iodine when using salt from the retailers $(7 \%, \mathrm{n}=2)$ or salt observed at the household level $(6 \%, n=2)$. study and not a monitoring and evaluation activity within the iodization programme.

Our findings show how the iodization and management of the supply-chain is currently not providing salt with sufficient iodine concentrations to the adults and pregnant women living in the target area. It is important to note that the decrease is more profound at the retailer and consumer levels. The losses are comparable with data documented from Nepal (31). In another study, Taga et al. measured large decreases in iodine concentration of salt at various points in the supply-chain and documented losses of around 44.8-82.3\% (14). Similarly, different authors have described a high variability of iodine concentrations at the retailer or household levels (12,14-16,18-20,24).

The findings presented here show that the losses of iodine are considerable. Only the concentrations at the production site were sufficient to ensure an adequate intake. The loss in iodine concentration at the household level is more than that estimated by the $\mathrm{WHO}-\mathrm{a}$ reduction of $20 \%$ of iodine concentration from the production to the household level (10). The iodine concentration is anticipated to decrease further with additional losses during cooking. Using an additional 20\% loss during cooking, it is apparent that a very few pregnant women are expected to consume sufficient iodine.

Contrary to previous findings (32), we did not observe co-existence of lower and higher iodine concentrations in salt in the households in the same

Table. Estimated iodine intake based on iodine concentration in salt from different sampling units at production, retailer and household levels

\begin{tabular}{|c|c|c|c|c|c|c|c|}
\hline \multirow{2}{*}{$\begin{array}{l}\text { Place } \\
\text { of } \\
\text { sampling }\end{array}$} & \multirow{2}{*}{ No. } & \multirow{2}{*}{$\begin{array}{c}\begin{array}{c}\text { Mean iodine } \\
\text { intake } \pm S D\end{array} \\
(\mu \mathrm{g} / \text { day })\end{array}$} & \multirow{2}{*}{$\begin{array}{c}\begin{array}{c}\text { Range of io- } \\
\text { dine intake }\end{array} \\
(\mu g / \text { day })\end{array}$} & \multicolumn{2}{|c|}{$\begin{array}{c}\text { Exposure assessment } \\
\text { not adjusted for } \\
\text { cooking losses }\end{array}$} & \multicolumn{2}{|c|}{$\begin{array}{c}\text { Exposure assessment } \\
\text { adjusted for cooking } \\
\text { losses* }\end{array}$} \\
\hline & & & & $\begin{array}{c}\text { Units } \\
<150 \mu \mathrm{g} / \\
\text { day }(\%)^{\ddagger}\end{array}$ & $\begin{array}{c}\text { Units } \\
<250 \mu \mathrm{g} / \\
\text { day }(\%)^{\ddagger}\end{array}$ & $\begin{array}{c}\text { Units } \\
<150 \mu g / \\
\text { day }(\%)^{\ddagger}\end{array}$ & $\begin{array}{c}\text { Units } \\
<250 \mu g / \\
\text { day }(\%)^{\ddagger}\end{array}$ \\
\hline Production & 41 & $266.3 \pm 70.4$ & $92.5-452.6$ & 5 & 41 & 18 & 70 \\
\hline Retailer & 7 & $189.0 \pm 65.8$ & $136.2-311.4$ & 27 & 82 & 49 & 93 \\
\hline Household & 32 & $115.5 \pm 103.5$ & $5.1-321.1$ & 63 & 90 & 71 & 94 \\
\hline
\end{tabular}

${ }^{*}$ WHO estimates that $20 \%$ of iodine is lost during cooking; $\$ 150 \mu \mathrm{g} / \mathrm{g} /$ day is the minimum requirement for iodine intake in an adult; $\uparrow 250 \mu \mathrm{g} / \mathrm{g} /$ day is the minimum requirement for a pregnant woman; $\mathrm{SD}=$ Standard deviation; $\mathrm{WHO}=$ World Health Organization

\section{DISCUSSION}

The study, for the first time, evaluated the losses of iodine occurring under local conditions between the time of iodization and the time of consumption in Ethiopia. This investigation is an independent community. The iodine concentrations in salt were overall low in the different samples.

One way to deliver sufficient iodine at the household level is to increase the concentration of iodine at the production site. This would, however, 
potentially expose consumers to excess intake levels. Taking into account the observed losses in the present study and those expected during cooking, a concentration of $119.2 \mathrm{mg} / \mathrm{kg}$ is needed at the production site to protect $50 \%$ of pregnant women. This concentration is double of what was measured in the study. When salt with this concentration is consumed, it would expose $31 \%$ of adults to intakes higher than the tolerable upper intake level of 600 $\mu \mathrm{g}$ per day according to the EC/SCF (29). Taking into account the losses observed after production, no consumers would be exposed to unacceptable high intake levels when this salt is consumed at the retailer or household level.

The observation of the magnitude of losses, however, and of the scarcity of published data from other iodization programmes is worrying and calls for additional studies to determine the actual concentration of iodine consumed at the household level.

There are several limitations to this study. We were unable to carry out an assessment of exposure for children as there was no average salt-intake estimate for this age-group. This limits the application of our findings to the whole population. Seasonal variations and changes in climatic conditions are expected to affect the concentration of iodine in salt. The findings of the study might, therefore, vary over the year, and our conclusions can only be related to the study season. In addition, the study area is located $50 \mathrm{~km}$ away from the production site, is semi-urban, and is relatively closer to the production site than many other outlet facilities in the region. Since losses of iodine are expected to increase with longer supply lines, the selection of this town might have underestimated the level of iodine loss.

Another limitation is the low sample size of the study. This may have affected our estimates on the variability of iodine in the samples and overestimated the probable effects to some extent. We are confident, however, that our point estimates are accurate and that our conclusions relating to the reduction of iodine in the samples are robust. Despite the small sample size, this study provides evidence to justify further research to study the populationwide effects of iodine losses in salt under field conditions.

We argue that the bias of the study area (a community study site) is minimal since this was the first time this area was selected for research with regard to iodine or salt.

Due to the cross-sectional nature of the study, we were unable to accurately determine the effect of time on the reduction of iodine concentration after production. There was no registration mechanism which allowed us to determine the exact production date and age of salt analyzed from the retailer and at the household level. The iodization date of salt was not recorded on the packages. Salt-bags from different production batches are mixed once they reach the retailer level. From the accounts of the retailers and households, we estimated that salt sold at the retailer level was iodized 2-3 months earlier. The salt sampled in the households originated from the same batch of production as the salt analyzed from the retailers and was stored an additional 1-2 months at home before analysis. We carried out an assessment of exposure assuming that iodine in the diet is negligible. As described earlier, the study area-Tigray region-is one of the highest affected areas by iodine deficiency in the country (26). We argue from this that the endogenous dietary supply of iodine is minimal and is not expected to affect the findings of our study.

The iodization of salt was done using potassium iodate, which is considered the most stable form for iodization in tropical climates $(10,11)$. The measurement of the moisture content, impurities, and acidity/alkalinity of salts at the production, retailer and household levels could have been helpful in explaining the significant loss of iodine concentration at the retailer and consumer levels.

Recommendations for iodine concentration of salt at the production level need to take into account local losses to ensure adequate iodine intake. Our findings call for the establishment of local standards for salt iodine levels. In addition, storing of salt in a dry place and a clean airtight plastic container and also avoiding excess exposure to sunlight and heat could possibly reduce the level of post-production loss of iodine at the retailer and consumer levels.

The findings clearly have important implications for the development of post-production qualitycontrol and monitoring schemes, particularly during salt distribution and storage. A monitoring and evaluation system needs to be in place along the chain to ensure the adequate supply of iodine. This should also include printing of the production date on salt packets. Specific attention and collaboration with the retailers is necessary to address the loss of iodine at this level of the chain. Creation of awareness about proper storing and handling of iodized salt may prevent possible loss of iodine at the retailer and consumer levels.

\section{ACKNOWLEDGEMENTS}

The authors gratefully acknowledge the financial support of the Mekelle University and NORAD II 
project. They thank Mr. Tekelit Gebregiorgies and Tame Kiros for their work during laboratory analysis. Special appreciation goes to Afework Mulugeta, Yemane Ashber, and Awala Equar, community health internship students, the salt-producing company, retailers, and consumers at Wukro district for their contribution to data collection of the study. The authors also thank Anne Mullen for the language revisions.

\section{REFERENCES}

1. Hetzel BS. Iodine deficiency disorders (IDD) and their eradication. Lancet 1983;2:1126-9.

2. Laurberg P, Nøhr SB, Pedersen KM, Hreidarsson AB, Andersen S, Bülow Pedersen I et al. Thyroid disorders in mild iodine deficiency. Thyroid 2000;10:951-63.

3. World Health Organization. Iodine status worldwide: WHO global database on iodine deficiency. Geneva: World Health Organization, 2004. 48 p.

4. Andersson M, Takkouche B, Egli I, Allen HE, de Benoist B. Current global iodine status and progress over the last decade towards the elimination of iodine deficiency. Bull World Health Organ 2005;83:51825.

5. Bleichrodt N, Born MP. A metaanalysis of research on iodine and its relationship to cognitive development. In: Stanbury J, editor. The damaged brain of iodine deficiency. New York, NY: Cognizant Communication, 1994:195-200.

6. Ethiopia. Ministry of Health. Towards universal salt iodization in Ethiopia. Addis Ababa: Ministry of Health, 2006. 4 p.

7. Mannar MGV. Control of iodine deficiency disorders by iodization of salt: strategy for developing countries. In: Hetzel BS, Dunn JT, Stanbury JB, editors. The prevention and control of iodine deficiency disorders. Amsterdam: Elsevier, 1987:111-25.

8. Zhao J, van der Haar F. Progress in salt iodization and improved iodine nutrition in China, 1995-99. Food Nutr Bull 2004;25:337-43.

9. Lamberg BA. Effectiveness of iodized salt in various part of the world. In: Hall R, Kobberling J, editors. Thyroid disorders associated with iodine deficiency and excess. New York, NY: Raven Press, 1985;22:8194.

10. World Health Organization. Assessment of iodine deficiency disorders and monitoring their elimination: a guide for programme managers. 3rd ed. Geneva: World Health Organization, 2008. 98 p.

11. Kelly FC. Studies on the stability of iodine compounds in iodized salt. Bull World Health Organ 1953;9:21730.
12. Takele L, Belachew T, Bekele T. Iodine concentration in salt at household and retail shop levels in Shebe town, south west Ethiopia. East Afr Med J 2003;80:532-9.

13. Sebotsa ML, Dannhauser A, Jooste PL, Joubert G. Iodine content of salt 2 years after the introduction of the universal salt iodisation legislation in Lesotho. $\mathrm{Br}$ J Nutr 2005;93:917-22.

14. Taga I, Massouké DD, Ndomou M, Yonkeu JN. [Iodized salt in Cameroon]. Sante 2004;14:161-5 [French].

15. Bansal RK. An operations research study on salt consumption behaviour with respect to its iodine content. Indian J Matern Child Health 1995;6:80-3.

16. Jooste PL, Weight MJ, Lombard CJ. Iodine concentration in household salt in South Africa. Bull World Health Organ 2001;79:534-40.

17. Jooste PL, Weight MJ, Locatelli-Rossi L, Lombard CJ. Impact after 1 year of compulsory iodisation on the iodine content of table salt at retailer level in South Africa. Int J Food Sci Nutr 1999;50:7-12.

18. Assey VD, Peterson S, Greiner T. Sustainable universal saltiodizationinlow-incomecountries-timetorethink strategies? Eur J Clin Nutr 2008;62:292-4.

19. Sebotsa ML, Adjei R. The evaluation of the iodine content of table salt in Lesotho. Afr J Health Sci 2002;9:139-45.

20. Avinash KR, Prabha Adhikari MR. Iodine content of various salt samples sold in Mangalore-a coastal city with endemic goitre. J Assoc Physicians India 2002;50:1146-8.

21. Biber FZ, Unak P, Yurt F. Stability of iodine content in iodized salt. Isotopes Environ Health Stud 2002;38:8793.

22. Wang GY, Zhou RH, Wang Z, Shi L, Sun M. Effects of storage and cooking on the iodine content in iodized salt and study on monitoring iodine content in iodized salt. Biomed Environ Sci 1999;12:1-9.

23. Oshinowo T, Diosady L, Yusufali R, Laleye L. Stability of salt double-fortified with ferrous fumarate and potassium iodate or iodide under storage and distribution conditions in Kenya. Food Nutr Bull 2004;25:26470.

24. Jooste PL. Assessment of the iodine concentration in table salt at the production stage in South Africa. Bull World Health Organ 2003;81:517-21.

25. Ethiopia. Central Statistical Agency. Ethiopia demographic and health survey 2005. Addis Ababa: Central Statistical Agency, 2006. 448 p.

26. Ethiopia. Ministry of Finance and Economic Development. Population Department. Ethiopia: population images, 2006. Addis Ababa: Population Department, 
Ministry of Finance and Economic Development, Government of Ethiopia, 2007. 20 p.

27. Mannar VMG, Dunn JT. Salt iodization for the elimination of iodine deficiency. Ottawa: International Council for Control of Iodine Deficiency Disorders, 1995. $133 \mathrm{p}$.

28. Abuye C, Berhane Y, Akalu G, Getahun Z, Ersumo T. Prevalence of goiter in children 6 to 12 years of age in Ethiopia. Food Nutr Bull 2007;28:391-8.

29. Anderson M, de Benoist B, Darnton-Hill I, Delange F. Iodine deficiency in Europe: a continuing public health problem. Geneva: World Health Organiza- tion, 2007. $70 \mathrm{p}$.

30. Thomson BM, Vannoort RW, Haslemore RM. Dietary exposure and trends of exposure to nutrient elements iodine, iron, selenium and sodium from the 2003-4 New Zealand total diet survey. Br J Nutr 2008;99:61425.

31. Joshi AB, Banjara MR, Bhatta LR, Rikimaru T, Jimba $\mathrm{M}$. Insufficient level of iodine content in household powder salt in Nepal. Nepal Med Coll J 2007;9:75-8.

32. Adou P, Aka D, Aké M, Koffi M, Tébi A, Diarra-Nama AJ. [Assessment of iodine content of dietary salt in Abidjan Côte d'Ivoire)]. Sante 2002;12:18-21 [French]. 